\title{
Simplified approaches for Arias Intensity correction of synthetic accelerograms
}

\author{
Zheng $\mathrm{Li}^{1} \cdot$ Panagiotis Kotronis ${ }^{2} \cdot$ Hanliang $\mathrm{Wu}^{3}$
}

\begin{abstract}
For the generation of synthetic accelerograms, spectrum compatibility is usually emphasized. However, it is well known that the correct evaluation of the seismic response depends on suitable seismic inputs. For example, Arias Intensity, that measures the energy of an earthquake and which attracts more and more attention in probabilistic seismic analysis, cannot be ignored. Thus, simplified methods which could generate both spectrumcompatible and energy-compatible accelerograms are required. This study focuses on the correction of Arias Intensity when generating artificial synthetic accelerograms for given specific earthquake records. Two simple and efficient approaches are proposed. The first approach introduces an energy-compatible algorithm to the spectrum-compatible model, which enables the generated accelerograms to match both the target response spectrum in the frequency domain and Arias Intensity in the time domain. The second approach refers to an empirical way in which empirical envelope shape functions are directly defined based on the energy distribution profile of given earthquake records. The two approaches are validated using various earthquake records, their performance is proven satisfactory and their application is straightforward in the relative fields of earthquake engineering.
\end{abstract}

Hanliang Wu

hanliang.wu@hotmail.com; hl.wu@rioh.cn

Zheng Li

lizheng619@hotmail.com; zheng.li@bjut.edu.cn

Panagiotis Kotronis

Panagiotis.Kotronis@ec-nantes.fr

1 Key Laboratory of Urban Security and Disaster Engineering of Ministry of Education, Beijing University of Technology, Pingleyuan No. 100, Chaoyang District, Beijing 100124, China

2 Ecole Centrale de Nantes, Université de Nantes, CNRS, Institut de Recherche en Génie Civil et Mécanique (GeM), 1 Rue de la Noë, 44321 Nantes, France

3 Research Institute of Highway Ministry of Transport, 8 Xitucheng Road, Haidian District, Beijing, China 
Keywords Arias Intensity - Synthetic accelerograms · Spectrum-compatible · Energy-compatible $\cdot$ Energy-based envelope shapes

\section{Introduction}

Modern building codes or guidelines usually adopt design response spectra to define the seismic load. For this reason and when transient dynamic analysis are necessary, it is often required that the spectra of the input accelerograms are similar to or envelope the prescribed target design spectra. This kind of seismic inputs are called spectrum-compatible accelerograms. Spectrum-compatible time histories received great popularity for earthquake design (Naeim and Lew 1995) and different spectrum-compatible models have been proposed (Gasparini and Vanmarcke 1976; Kaul 1978; Iyengar and Rao 1979; Cacciola et al. 2004; Zentner and Poirion 2012). Spectrum-compatible models are also widely used for performance based safety assessment and probabilistic risk assessment studies (Zentner et al. 2011).

Recently, the importance of the seismic input for a correct evaluation of the seismic response has been highlighted (Kwon and Elnashai 2006; Nanos and Elenas 2006; Masi et al. 2011). Actually, the nonlinear dynamic response is highly influenced by the nonstationary behavior of the input signals in both time and frequency domains (Yeh and Wen 1990; Wang et al. 2002; Spanos et al. 2007). Zentner and Poirion (2012) pointed out the need to correctly reproduce the natural variability of the ground motion parameters (such as peak ground acceleration (PGA), cumulative absolute velocity and Arias Intensity) observed for recorded time histories. Masi (2003) reported that integral intensity measures, such as the Arias Intensity (Arias (1970)), are very effective in representing the damage potential of a ground motion. Arias Intensity can be seen as the premise that the damage experienced during an earthquake is proportional to the energy per unit weight dissipated by the structure during the total duration of the earthquake (Villaverde 2009).

The effectiveness of Arias Intensity in predicting the likelihood of damage of shortperiod structures has been recently demonstrated (Travasarou et al. 2003). Arias Intensity can be considered as a suitable ground motion measure in probabilistic seismic hazard analysis (PSHA) (Stafford et al. 2009a). For a better seismic risk assessment, Cabañas et al. (1997) look at Arias Intensity as a parameter to relate the energy of the ground motion and the damage occurrence. It has been shown that the Local Medvedev-Sponheuer-Karnik (MSK) Intensity has good correlation with Arias Intensity (Cabañas et al. 1997). Arias Intensity as ground motion measure can also be applicable in geotechnical engineering such as in the determination of rock falls and landslides occurence (Harp and Wilson 1995; Del Gaudio et al. 2003) or liquefaction (Egan and Rosidi 1991; Kayen and Mitchell 1997; Kramer and Mitchell 2006).

Acknowledging the importance of Arias Intensity (energy content) in seismic analysis, it is necessary to reproduce a reasonable Arias Intensity for the seismic input. In other words, besides a spectrum compatibility the energy compatibility of the seismic input should be sought. Different studies have been proposed to generate energy-compatible accelerograms. Yazdani and Takada (2009) proposed a wavelet based method to generate artificial earthquake signals that are both energy and spectrum compatible. Sheng et al. (2012) used the wavelet method to adjust the energy of multi-dimensional ground motions. 
Stafford et al. (2009b) proposed an energy-based envelope function for the stochastic simulation of earthquake accelerograms.

Based on the well-known spectrum-compatible model proposed by Gasparini and Vanmarcke (1976), two simplified approaches are proposed in this paper to improve the Arias Intensity of the (energy-compatible) synthetic accelerograms. For specific earthquake records, the proposed two methods are proven simple, efficient, enabling both spectrum and energy compatibility in time and frequency domain.

\section{Spectrum-compatible model}

Among the synthetic accelerogram generation models (Gasparini and Vanmarcke 1976; Kaul 1978; Iyengar and Rao 1979; Cacciola et al. 2004; Rezaeian and Kiureghian 2008, 2010; Rezaeian 2010; Zentner and Poirion 2012), the most popular and commonly used is probably the one proposed in 1976 by Gasparini and Vanmarcke (1976), for its simplicity and efficiency. The advantage of this model is that the spectra of the generated accelerograms are directly matched with the target spectrum (either the spectrum from a recorded earthquake or the spectrum from design codes). This method is nowadays introduced in various softwares (Masi et al. 2011; Zentner et al. 2014), for example SeismoArtif (Seismosoft 2016). In the Gasparini-Vanmarcke model, the artificial accelerograms are generated by a series of modulated sinusoidal waves, see Eq. (1):

$$
a(t)=q(t) \sum_{i=1}^{n} A_{i} \sin \left(\omega_{i} t+\Phi_{i}\right)
$$

where $q(t)$ is a deterministic envelope function (or modulating function), defining the transient temporal earthquake nonstationary; $A_{i}, \omega_{i}$ and $\Phi_{i}$ are respectively the amplitude, frequency and phase angle of the $i$ th sinusoidal wave. In order to match the prescribed target spectrum, the amplitudes $A_{i}$ have to be adjusted and corrected. ${ }^{1}$ Normally, this correction is an iterative process. A simple iterative linear correction could be applied (Gasparini and Vanmarcke 1976), see Eq. (2). For the $j$ th iteration:

$$
A_{j+1}=\frac{S_{v, \text { target }}}{S_{v, \text { computed }}} A_{j}
$$

where $S_{v}$ is the velocity spectrum. Since for elastic response spectrum, $S_{a}=\omega_{d} S_{v}$, Eq. (3) is derived:

$$
A_{j+1}=\frac{S_{a, \text { target }}}{S_{a, \text { computed }}} A_{j}
$$

The recommended number of iterations is $j \geq 3$. A greater iteration number results in a more precise matching with the target spectra increasing however the necessary computational time.

In this study, instead of using a fixed number of iterations, a convergence criterion is adopted. More specifically, Eq. (4) is used to evaluate the relative error between the target and the computed results.

\footnotetext{
1 The amplitudes $A_{i}$ are related to the Power Spectral Density Function (PSDF) as: $G\left(\omega_{i}\right) \Delta \omega=A_{i}^{2} / 2$.
} $G\left(\omega_{i}\right) \Delta \omega$ represents the contribution of the sinusoid with frequency $\omega_{i}$ to the total power of the motion. 


$$
R=\frac{\left\|X_{\text {target }}-X_{\text {computed }}\right\|}{\left\|X_{\text {target }}\right\|} \%
$$

where $R$ is the relative error; $X_{\text {target }}$ the target value and $X_{\text {target }}$ the computed value. The more strict is the tolerance (smaller $R$ ) the more iterations are required. It is found that with a tolerance of $R \leqslant \mathbf{T O L}=20 \%, 3-5$ iterations are usually needed to achieve convergence. Following this procedure, the artificial acceloergrams can be obtained by adjusting the amplitudes $A_{i}$. In this way, the spectrum matching is performed in the frequency domain.

Considering the time domain, the envelope $q(t)$ plays an important role on the properties of the generated accelerograms (Greco et al. 2014). Different envelope functions have been proposed in the literature such as a trapezoidal shape (Hou 1968) and a 'boxcar' (stationary) shape (Gasparini and Vanmarcke 1976) or other seismological indices based envelope (Marano et al. 2013). Three commonly used envelope functions are studied in this paper: (a) the exponential modulating envelope proposed by Liu (1969); (b) the piecewise envelope shape proposed by Jennings et al. (1968) and (c) the 'gamma' envelope curve proposed by Saragoni and Hart (1974). For more details on these envelope functions, refer to Appendix 1. The influence of the $q(t)$ envelope shape on the Arias Intensity (energy distribution) of the artificial accelerograms is highlighted hereafter.

The Arias Intensity $\left(I_{A}\right)$, introduced in 1970 by Arias (1970), is defined in Eq. (5):

$$
I_{A}=\frac{\pi}{2 g} \int_{0}^{t_{d}} a^{2}(t) d t
$$

where $a(t)$ denotes the ground acceleration; $g$ the gravitational acceleration; $t_{d}$ the total ground motion duration. The unit of Arias Intensity is $\mathrm{m} / \mathrm{s}$ (velocity). It characterizes the energy content of a strong motion record and captures the potential destructiveness of an earthquake (Travasarou et al. 2003). It is clear from Eq. (1) that $a(t)$ strongly depends on the modulating control function $q(t)$. To simulate the natural shape of a real earthquake record, the chosen envelope shape usually contains an 'ascending' and a 'descending' part. In addition, the total duration of the non-zero length of the envelope controls the final total cumulative energy. In other words, the 'shape' of the envelope $q(t)$ governs the energy distribution $a(t)$ of the simulated earthquake and therefore the Arias Intensity. For a given real earthquake record, if the modulating envelope is not properly defined, this will cause significant discrepancies between the Arias Intensity of the simulated and target accelerograms.

The model proposed by Gasparini and Vanmarcke (1976) generats accelerograms that are spectrum compatible with the target one. Nevertheless, the Arias Intensity compatibility (or energy distribution) is not guaranteed, results depend on the chosen modulation envelope function $q(t)$ in the time domain. Some examples are given hereafter.

All the earthquake records studied in this paper are listed in Table 1. A statistical analysis was also carried out with the Loma Prieta earthquake. As shown in Fig. 1, when the number of simulations approaches 1000, the mean PGA of the generated accelerograms is stable. In the following, all the statistic results presented are made using 1000 simulations.

The influence of the chosen envelope shape on the produced spectra and Arias Intensity is investigated hereafter. The Loma Prieta earthquake (Table 1) is chosen as the target earthquake. The response spectra damping ratio is set to $\xi=5 \%$. Considering the different envelope shapes $q(t)$ proposed (a) by Liu (1969), (b) by Jennings et al. (1968) and (c) by 
Table 1 Strong motion records

\begin{tabular}{lllrrr}
\hline Earthquake & Date & Station & $\mathrm{M}_{\mathrm{w}}$ & $\mathrm{R}_{\mathrm{e}}(\mathrm{km})$ & $\mathrm{PGA}(\mathrm{g})$ \\
\hline Kobe & $1995-01-16$ & JMA, 0 & 6.9 & 1.0 & 0.821 \\
Imperial Valley & $1940-05-19$ & El Centro, 180 & 6.9 & 12.2 & 0.319 \\
Loma Prieta & $1989-10-18$ & Gilroy Array station \#1, 090 & 7.0 & 2.8 & 0.442 \\
Northridge newhall & $1994-01-17$ & Fire station, 090 & 6.7 & 10.9 & 0.583 \\
\hline
\end{tabular}

Note: 1. Strong motion records are extracted from the COSMOS (Consortium of Organizations for StrongMotion Observation Systems), COSMOS Strong-Motion Virtual Data Center. http://www.cosmos-eq.org/; http://www.strongmotioncenter.org/vdc/scripts/default.plx

2. $\mathrm{M}_{\mathrm{w}}$, moment magnitude of an earthquake; $\mathrm{R}_{\mathrm{e}}$, closest distance to fault

Fig. 1 Number of simulations versus mean of PGA of generated accelerograms. Loma Prieta earthquake (Table 1)

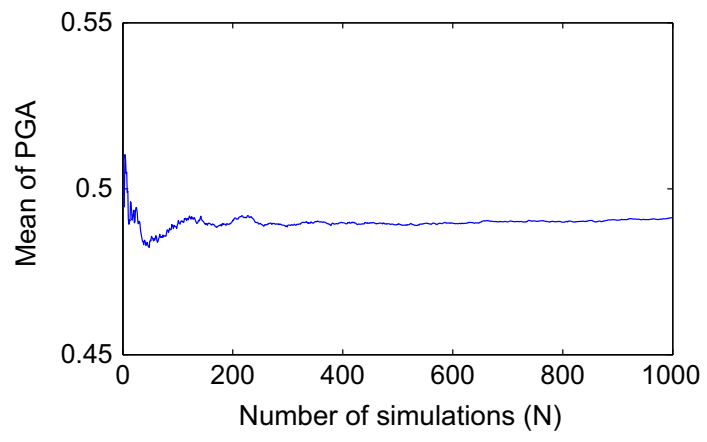

Saragoni and Hart (1974) and after matching the spectrum with the target $(\mathbf{T O L}=20 \%$ ), results in terms of spectra and Arias Intensity are shown in Figs. 2 and 3 respectively.

As often mentioned in the literature, the model proposed by Gasparini and Vanmarcke (1976) ensures the spectrum compatibility in the frequency domain, see Fig. 2. Results however are different in terms of Arias Intensity. Figure 3 shows the Arias Intensities from the simulated and the target accelerograms. The dash line and the shaded area denotes the mean Arias Intensity of 1000 simulations and its standard deviation, respectively. It can be seen that none of the three envelope shapes can effectively provide similar Arias Intensity with the target earthquake. In time domain, the $q(t)$ envelope shape has a significant influence on the Arias Intensity of the simulated accelerograms and should be properly tuned.

The influence of the amplitude of the envelope shape on the spectrum and Arias Intensity is presented hereafter. Consider the piece-wise envelope shape $q(t)$ proposed by Jennings et al. (1968) (Appendix 1). The artificial accelerograms are matched with the target Kobe earthquake (Table 1) with the same piece-wise envelope shape but different amplitudes i.e. $q(t), 0.5 q(t)$ and $0.2 q(t)$. The chosen parameters for $q(t)$ are $T_{1}=3.0$, $T_{2}=8.0$ and $\alpha=0.2$. The damping ratio of the response spectrum is $\xi=5 \%$. The comparisons of the resulting spectra and Arias Intensities are shown in Figs. 4 and 5, respectively. It can be seen that changing the amplitude of the envelope shape does not influence the matching of the spectra in frequency domain. In a similar way, the influence of the envelope shape amplitude on the Arias Intensity (time domaine) is negligible. This can be simply explained looking at Eq. (1). If $q(t)$ is amplified or reduced $m$ times during the iterative process in order to match the target spectrum, the amplitudes of the sine waves 
Fig. 2 Comparison of spectra of simulated and target accelerograms, Loma Prieta earthquake (Table 1), damping ratio $\xi=5 \%$. Simulated accelerograms using a the envelope shape by Liu (1969), b the Piece-wise envelope shape by Jennings et al. (1968) and c the 'Gamma' envelope shape by Saragoni and Hart (1974)
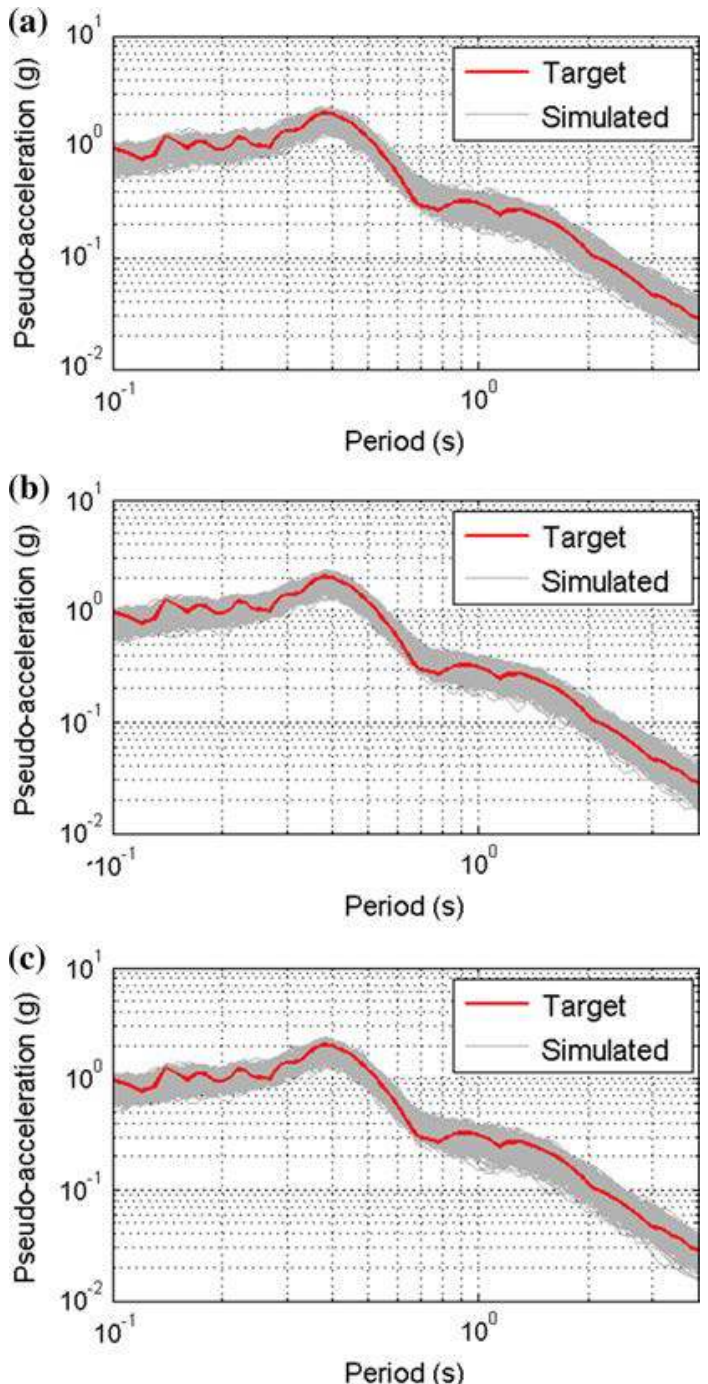

$A_{i}$ are automatically reduced or amplified by $1 / m$ times. Thus, the amplitude of the envelope shape $q(t)$ does not influence the spectrum and the Arias Intensity of the generated accelerograms.

The following conclusions can be therefore be made:

- the envelope shape $q(t)$ does not influence the matching of the spectra (frequency domain),

- the envelope shape $q(t)$ greatly influences the matching of the Arias Intensities (energy distribution, time domain),

- The Arias Intensities of the artificial accelerograms depend on the choice of the envelope shape $q(t)$.

Two novel simplified approaches are proposed hereafter to address these issues. 
Fig. 3 Comparison of Arias Intensities of simulated and target accelerograms (dash line mean value after 1000 calculations, shaded area standard deviation), Loma Prieta earthquake (Table 1 ), damping ratio $\xi=5 \%$. Simulated accelerograms using a the envelope shape by Liu (1969), b the Piece-wise envelope shape by Jennings et al. (1968) and c the 'Gamma' envelope shape by Saragoni and Hart (1974)
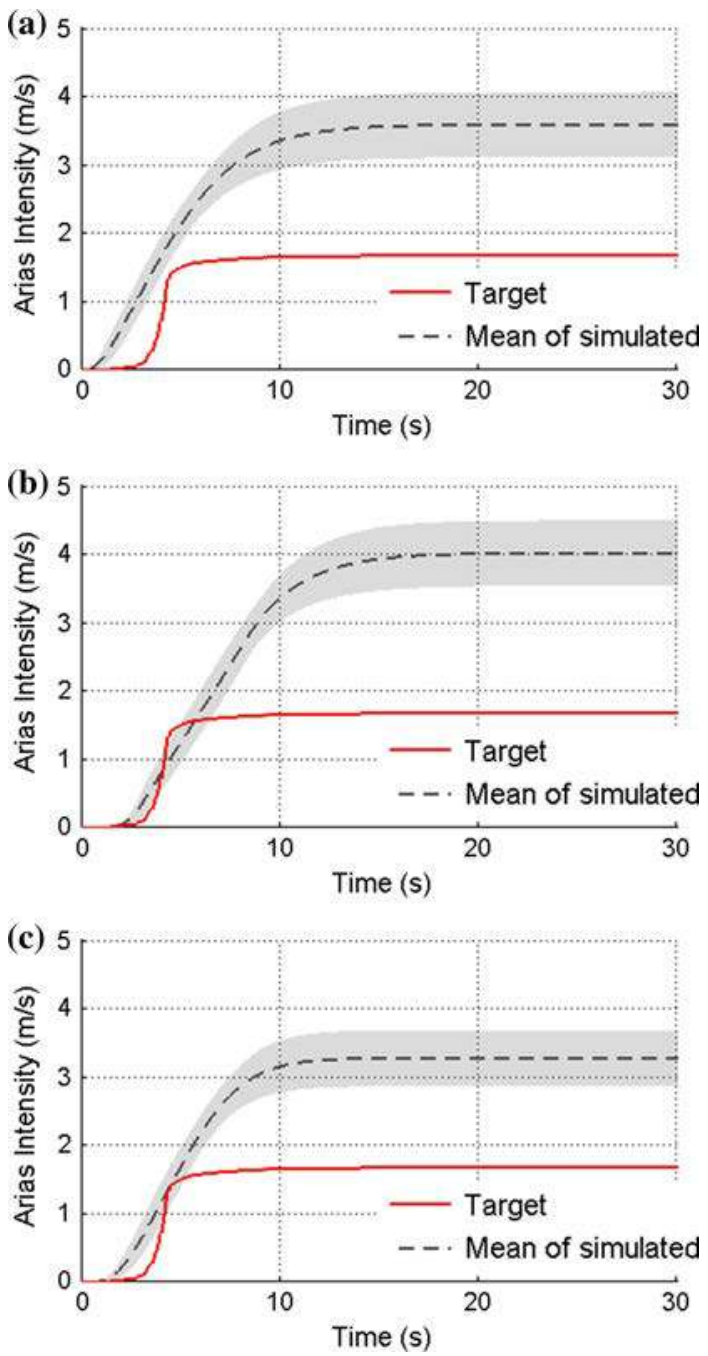

\section{Simplified approaches for Arias Intensity correction}

As mentioned in the previous section, due to the influence of the modulating function on the simulated artificial accelerograms, the resulting Arias intensities often have significant differences compared to the Arias intensities of the target recorded earthquake signals. In this section, two simplified approaches are introduced to correct the Arias Intensity of the generated synthetic accelerograms.

\subsection{Correcting Arias Intensity by matching the target energy distribution in time domain}

According to Gasparini and Vanmarcke (1976), $q(t)$ in Eq. (1) is a deterministic function which does not change in each iteration. It is proposed hereafter to abandon this hypothesis 
Fig. 4 Comparison of spectra of simulated and target accelerograms, Kobe (Table 1), damping ratio $\xi=5 \%$. Simulated accelerograms using the Piecewise envelope shape by Jennings et al. (1968). Envelope shape equals to a $q(t)$, b $0.5 q(t)$ and c $0.2 q(t)$
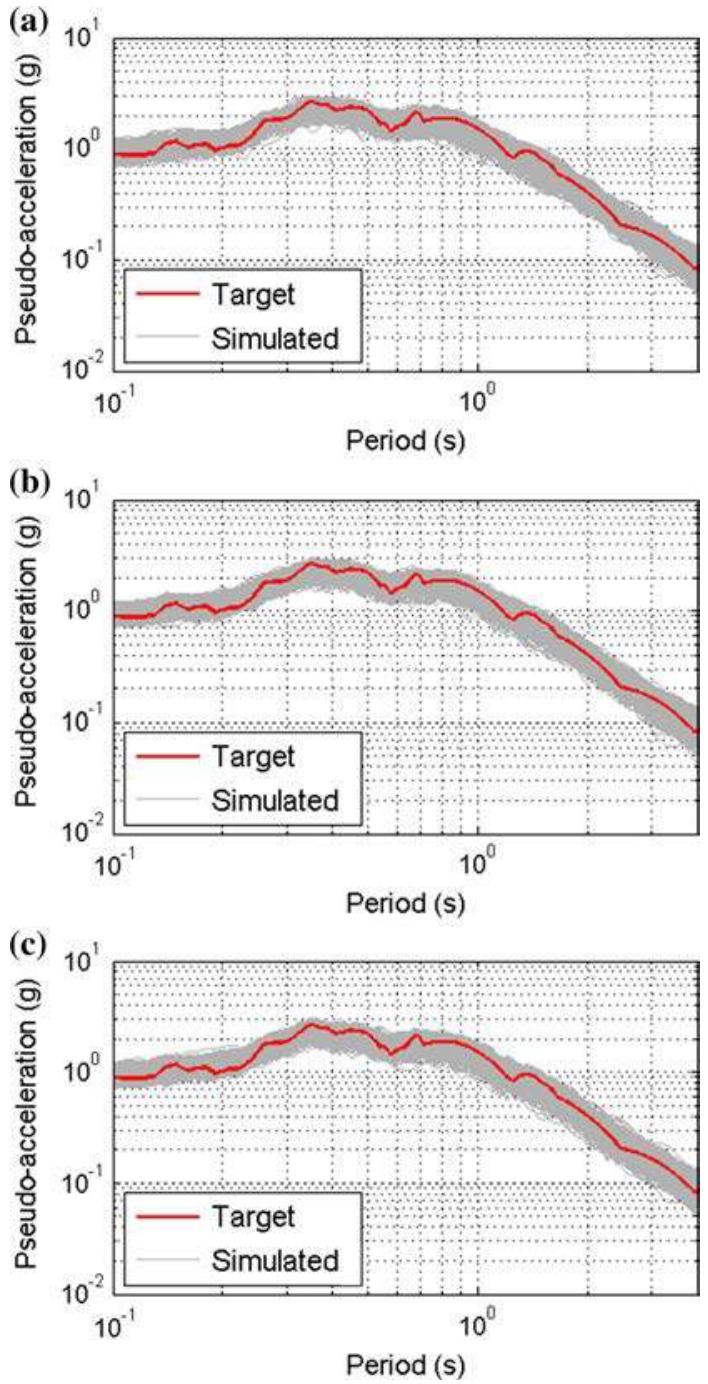

and to adjust $q(t)$ according to the differences between the target and simulated energy distributions such as to achieve energy compatibility at the end of the iterative procedure.

Arias Intensity is related to the energy content $E_{S}(t)$ of the earthquake signal, calculated as, Eq. (6):

$$
E_{s}(t)=\int_{0}^{t_{d}} a(t)^{2} d t
$$

$E_{s}(t)$ is the cumulative of the square of the ground acceleration $a(t)$. The Arias Intensity can be therefore seen as the variation of the earthquake energy $E_{s}(t)$. We note hereafter the content of $a(t)^{2}$ in time domain as $I(t)$, see Eq. (7): 
Fig. 5 Comparison of Arias Intensities of simulated and target accelerograms, Kobe (Table 1), damping ratio $\xi=5 \%$. Simulated accelerograms using the Piecewise envelope shape by (Jennings et al. 1968). Envelope shape equals to a $q(t)$, b $0.5 q(t)$ and c $0.2 q(t)$
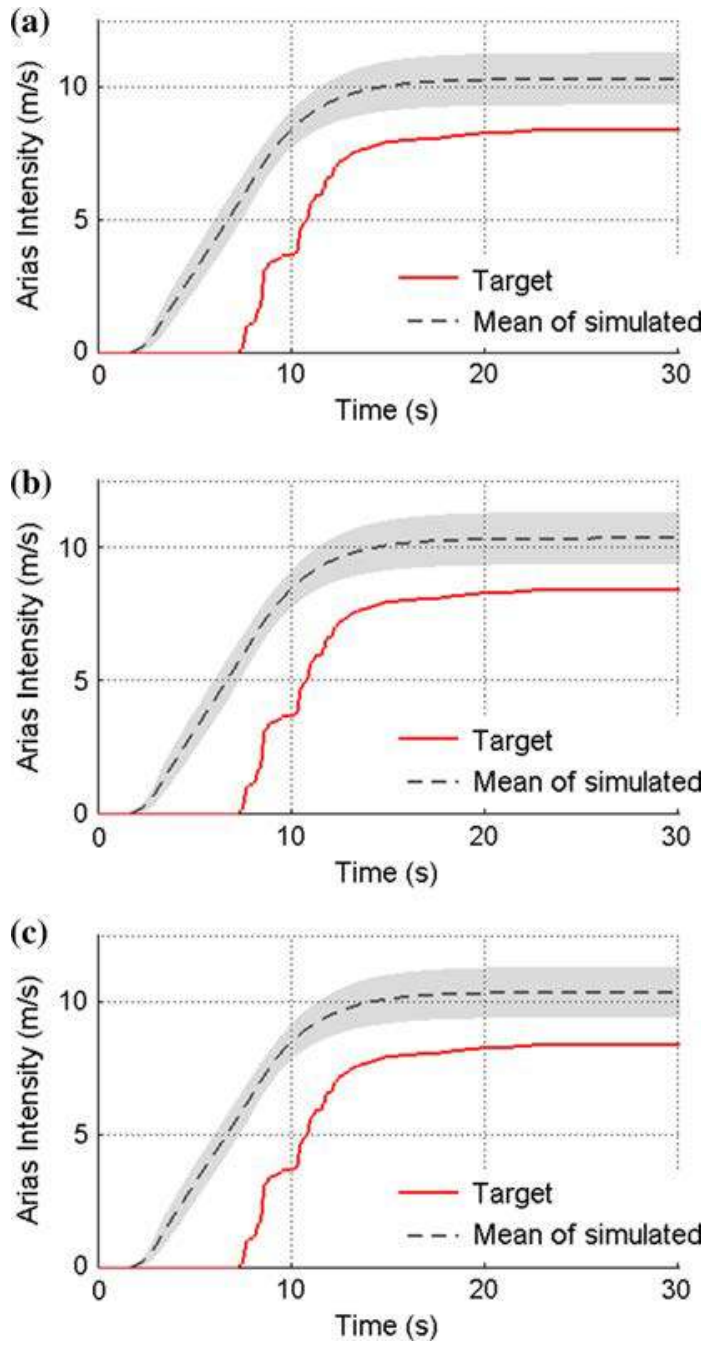

$$
I(t)=a(t)^{2}
$$

In order to achieve Arias Intensity (energy) compatibility, $I_{\text {computed }}(t)$ has to match the one of the target earthquake, $I_{\text {target }}(t)$. Then, the envelope shape function $q(t)$ should be accordingly adjusted based on the difference between $I_{\text {computed }}(t)$ and $I_{\text {target }}(t)$. To avoid convergence problems during the iterations, an averaged $I_{a}(t)$ is introduced instead of the original energy content $I(t) . I_{a}(t)$ is obtained by the Multiple-times Short-window Moving Averaging (MSMA) method. More specifically:

For certain time point $t_{i}, I_{a}\left(t_{i}\right)$ is defined as: 


$$
I_{a}\left(t_{i}\right)=\frac{I\left(t_{i-1}\right)+I\left(t_{i+1}\right)}{2}
$$

The procedure is to apply Eq. (8) several times until the averaged $I_{a}(t)$ is smoothed. The advantage of the MSMA method is that it results to very small modifications of the cumulative energy. Its effects on the energy distribution in time domain are clearly shown in Fig. 6. While increasing the times of averaging produces smoother curves, see Fig. 6a, the resulting cumulative energy stays always close to the original, see Fig. 6b. The Matlab subroutine for the Multiple-times Short window Moving Averaging method (MSMA) is provided in Appendix 1.

Similar to the spectrum matching process, the envelope $q(t)$ has to be adjusted iteratively. For the $j$ th iteration, $q(t)$ is updated according to Eq. (9):

$$
q(t)_{j+1}=\left(\frac{I_{a, \text { target }}}{I_{a, \text { computed }}}\right)^{p} q(t)_{j}
$$

where $q(t)_{j}$ and $q(t)_{j+1}$ are the envelope shapes of the $j$ th and $j+1$ th iterations; $I_{a, \text { target }}$ and $I_{a, \text { computed }}$ the target and computed energy distributions; $p$ a factor controling the convergence speed. The convergence criterion of Eq. (4) is again adopted. A double iterative algorithm is proposed to achieve spectrum-compatible and energy-compatible accelerograms, briefly summarized in the boxed Algorithm 1 (with $R_{1}$ and $\mathbf{T O L} \mathbf{L}_{\mathbf{1}}$ the error and tolerance respectively on spectra, $R_{2}$ and $\mathbf{T O} \mathbf{L}_{2}$ the error and tolerance on energies and $k$ the maximum number of iterations provided by the user.

Fig. 6 Effect of the Multipletimes Short window Moving Averaging method (MSMA) in time domain for the Kobe earthquake (Table 1) on a energy distribution $I(t)$, b cumulative energy $E_{s}(t)$

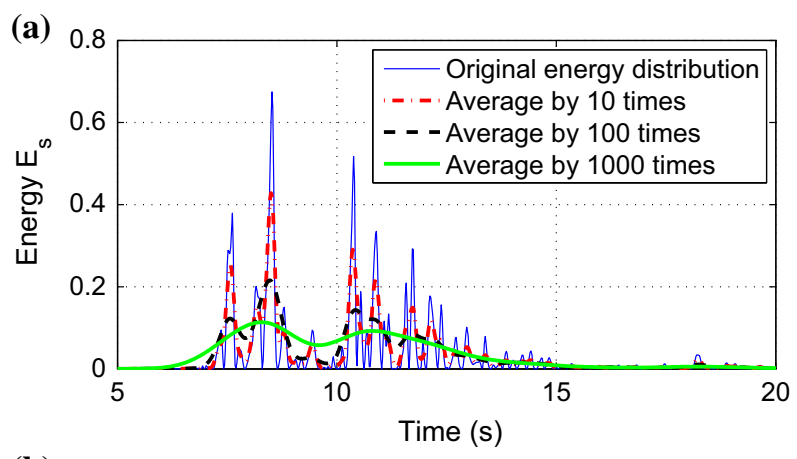

(b)

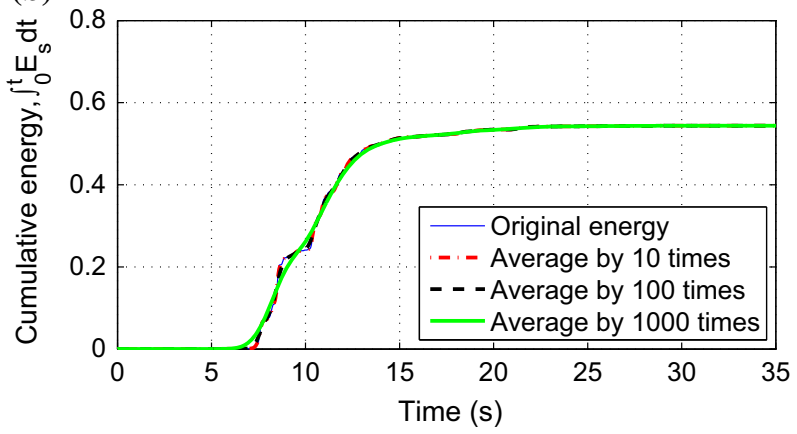


1. Initialize: generate randomly $A$ and $\Phi$; set $q(0)=(1, \ldots, 1), R_{1}=1, R_{2}=1$ and $k=1 ; \operatorname{read} p, \mathbf{T O L}_{\mathbf{1}}$ and $\mathbf{T O L} \mathbf{2}$;

2. Generate accelerogram: refer to Equation (1);

3. Matching target spectrum and energy distribution; while $R_{1}>\mathrm{TOL}_{1}$ or $R_{2}>\mathrm{TOL}_{2}$ do

Baseline correction ;

Compute spectrum and compare with target spectrum; compute $R_{1}$;

Adjust $A$, Equation (2);

Compute energy distribution and compare with target energy distribution; compute $R_{2}$;

Adjust $q(t)$, Equation (9);

if $k=k_{\text {max }}$ then

re-generate randomly $A$ and $\Phi$;

re-set $q(0)=(1, \ldots, 1)$;

re-generate accelerograms, Equation (1);

re-set $k=1$;

else

$k=k+1$

end

end

4. Finish;

Algorithm 1: Algorithm to achieve spectrum-compatible and energycompatible accelerograms by double iterative process

The two parallel iterations of the algorithm are interdependent. In order to easily obtain convergence, the factor $p$ in Eq. (9) has to be tuned to match the target spectrum first. After several numerical tests, the good values for $p$ are found to be about $0.1-0.3$. In the examples presented hereafter, $p=0.3$. In order to satisfy the two converge criteria, about 15-20 iterations are found to be necessary. At the beginning of the algorithm, a baseline correction (Boore 2001) is applied on the artificial accelerograms by subtracting the low frequencies from the signal. In this study, a simple linear polynomial curve is used to fit the time-history values which represents the low frequency component of the earthquake record. Then this linear fitting curve will be subtracted from the earthquake time-history.

An example of the simulated accelerograms using the spectrum-compatible and energy-compatible matching method for the Kobe earthquake is shown in Fig. 7. The adopted convergence criteria (tolerances) for spectrum and energy matching are $\mathbf{T O L}_{\mathbf{1}}=$ $20 \%$ and $\mathbf{T O L}_{\mathbf{2}}=10 \%$ respectively. The response spectrum damping ratio is $\xi=5 \%$. Comparisons of the spectra and Arias Intensities of the simulated and target accelerograms are shown in Fig. 8. Results show that both spectrum and Arias Intensity are well matched with the targets. Concerning energy compatibility, the mean of the simulated Arias Intensity follows closely the target one with a small standard deviation (shaded area). The proposed algorithm was further validated on other earthquakes. For example, results on the Elcentro earthquake (Table 1) with a higher spectrum damping ratio $\xi=$ $20 \%$ are shown in Fig. 9. 

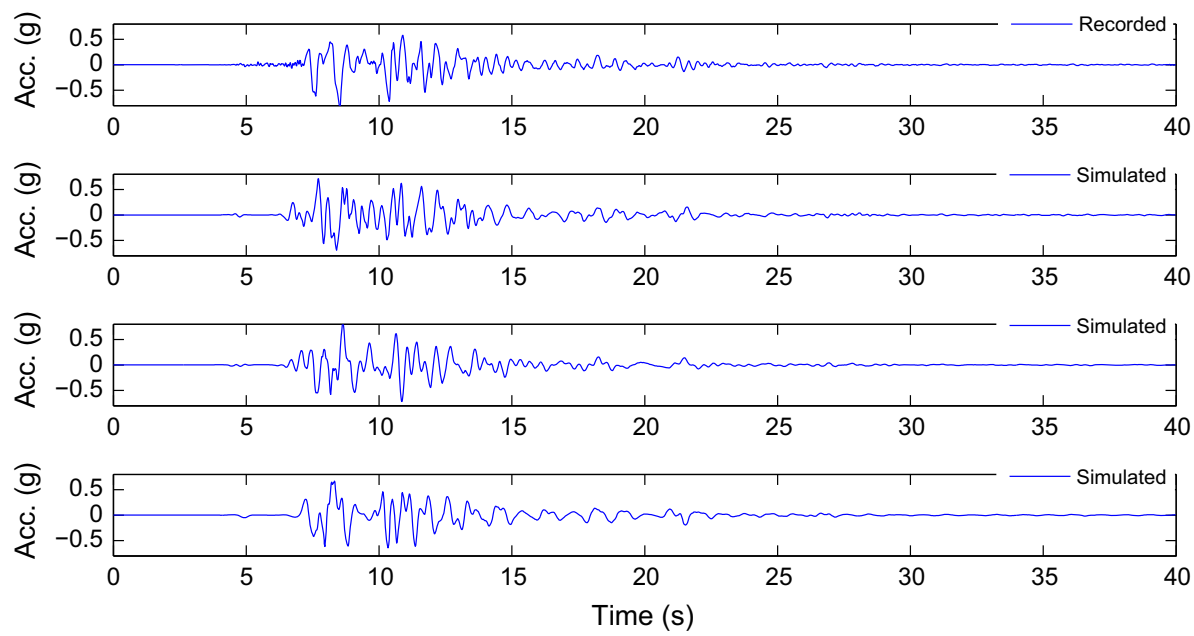

Fig. 7 Spectrum-compatible and energy-compatible accelerograms using the double iterative process of Algorithm 1. Kobe earthquake, JMA station, component: 0 . Response spectra damping ratio $\xi=5 \%$

Fig. 8 Comparison of simulated and target accelerograms using the double iterative process of Algorithm 1. Kobe earthquake (Table 1), damping ratio $\xi=5 \%$. a Spectra, b Arias Intensities
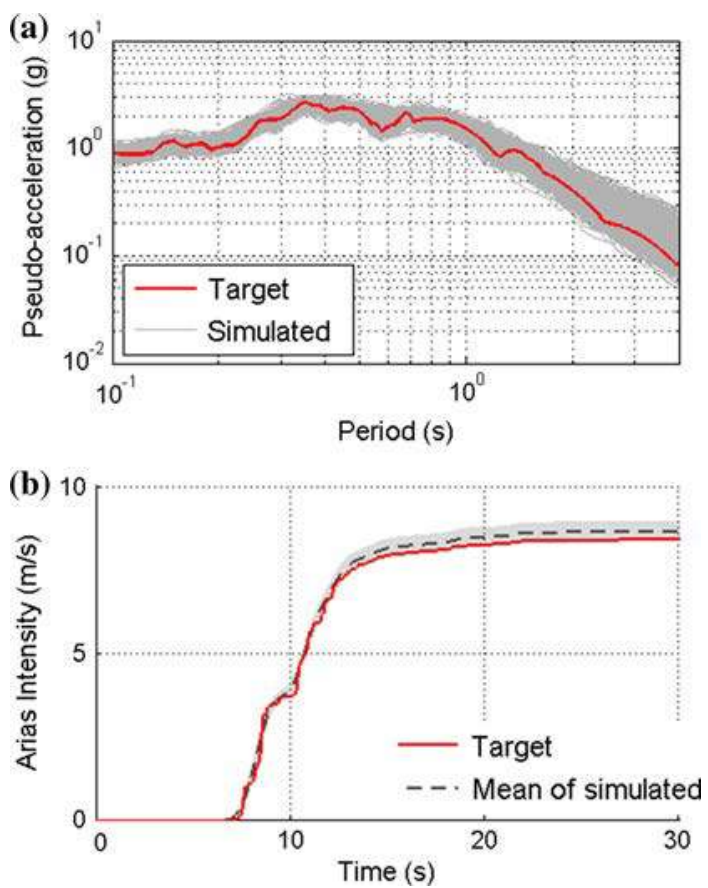

\subsection{Correcting Arias Intensity with an energy-based envelope shape}

In this section, an empirical and simple approach to correct the Arias Intensity of the artificial accelerograms is presented. The method adopts energy-based envelope shapes which can be directly obtained from the earthquake records. As discussed in Sect. 2, the 
Fig. 9 Comparison of simulated and target accelerograms using the double iterative process of Algorithm 1. Elcentro earthquake (Table 1), damping ratio $\xi=20 \%$. a Spectra, b Arias Intensities
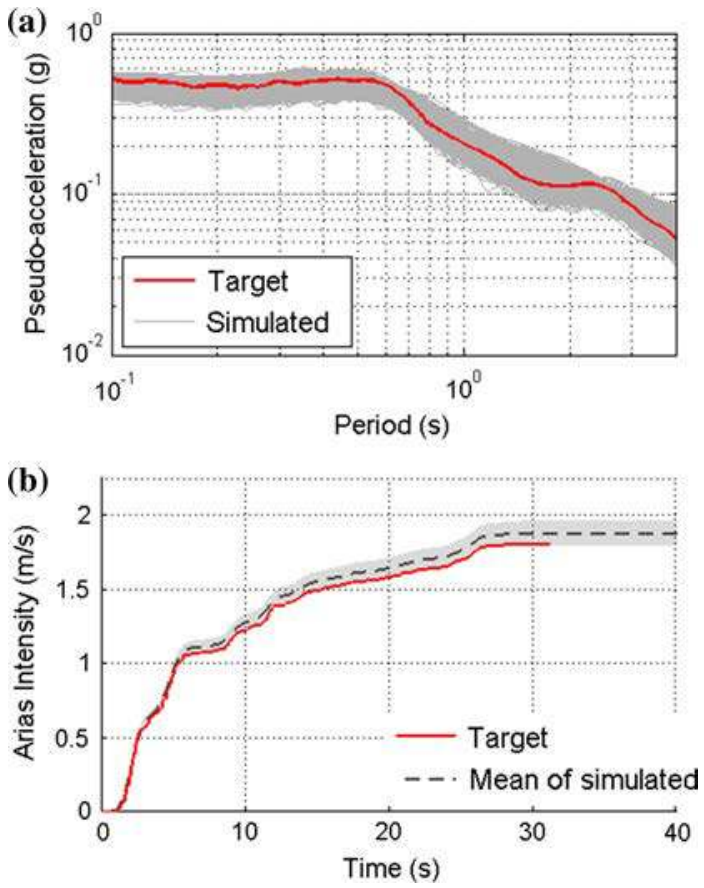

shape of the envelope function $q(t)$ plays an important role for the Arias Intensity of the generated accelerograms. The main idea is therefore to introduce the trend of the energy distribution of the recorded earthquake to the generated accelerograms, see Eq. (7). The definition of the new envelope shape is thus directly based on the energy distribution profile $I(t)$ of the target record.

Two examples of the energy-based envelope shapes (Loma Prieta and Northridge Newhall earthquakes) are shown in Fig. 10. It can be observed that each envelope shape is defined by the various peaks observed on the $I(t)$ profile. To find this curve, the procedure has as follows:

1. a first peak of $I(t)$ is identified at $\left(t_{0 \text { peak }}, I_{0 \text { peak }}\right)$ i.e. $\max (I(t))$;

2. for $t>t_{0 \text { peak }}$, a new peak is identified at $\left(t_{1 \text { peak }}, I_{1 \text { peak }}\right)$;

3. repeat this process until the time-history ends;

4. re-apply the procedure for $t<t_{0 \text { peak }}$;

5. apply a linear interpolation to plot the empirical envelope;

Algorithm 2: Algorithm to correct Arias Intensity with an energy-based envelope shape

The Matlab subroutine for finding the energy-based envelope shape is provided in Appendix 1. As discussed in Sect. 2, the amplitude of the envelope shape does not influence the spectrum and energy content of the artificial accelerograms. For simplicity reasons, the envelope shape is therefore normalized by its maximum value (see Fig. 10). The proposed empirical energy-based envelope represents approximately the ascending 
Fig. 10 a Energy-based envelope shape for the Loma Prieta earthquake (see Table 1), b energy-based envelope shape for the Northridge Newhall earthquake (see Table 1). acc in $\mathbf{a}$ and $\mathbf{b}$ represents the acceleration time-history of earthquake record (a)

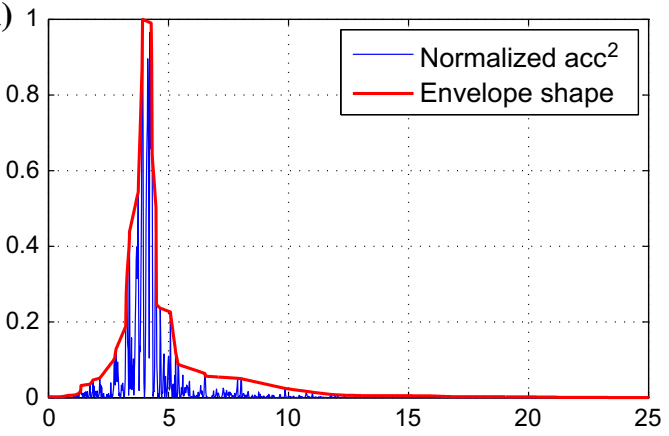

(b)

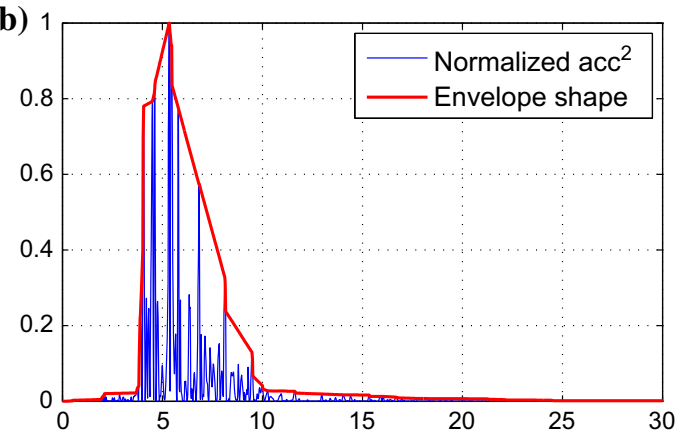

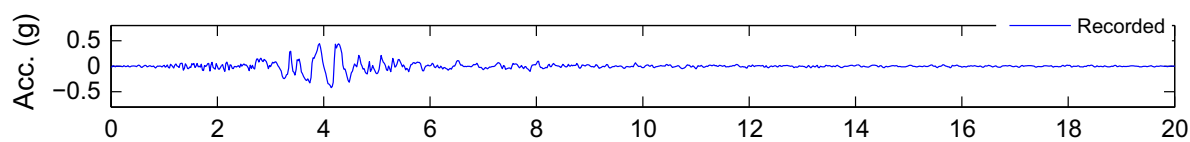
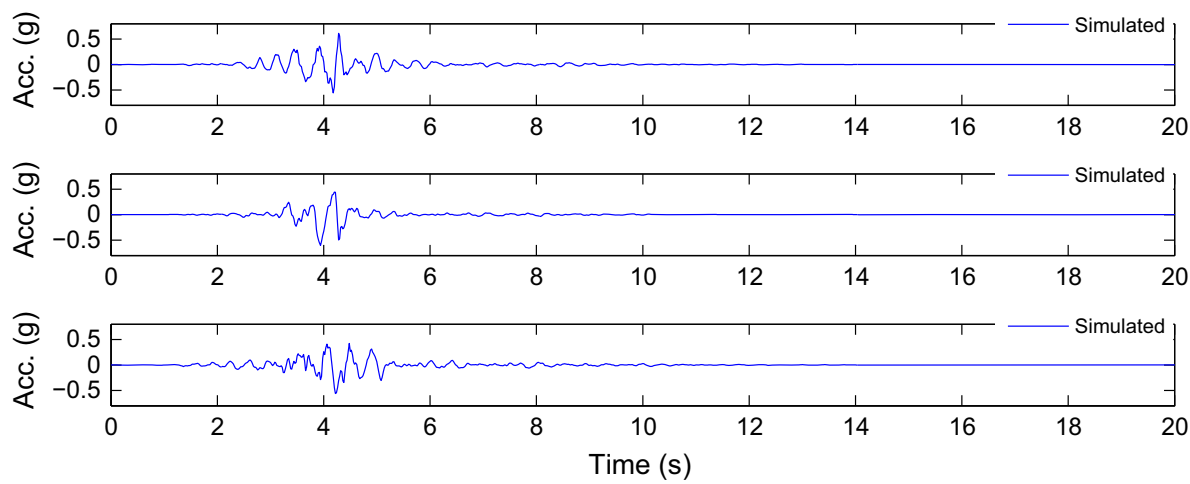

Fig. 11 Simulations of the Loma Prieta earthquake using an energy-based envelope shape. Response spectra damping ratio $\xi=5 \%$

and descending trends of the energy distribution. Furthermore, the total effective duration of an earthquake is well reflected. It is therefore expected that with this type of envelope shape, the generated artificial accelerograms will have similar spectra and Arias Intensities with the target one. 
Fig. 12 Comparison of simulated and target accelerograms using an energybased envelope shape. Loma Prieta earthquake (Table 1), damping ratio $\xi=5 \%$. a Spectra, b Arias Intensities

Fig. 13 Comparison of simulated and target accelerograms using an energybased envelope shape. Northridge Newhall earthquake (Table 1), damping ratio $\xi=20 \%$.

a Spectra, b Arias Intensities
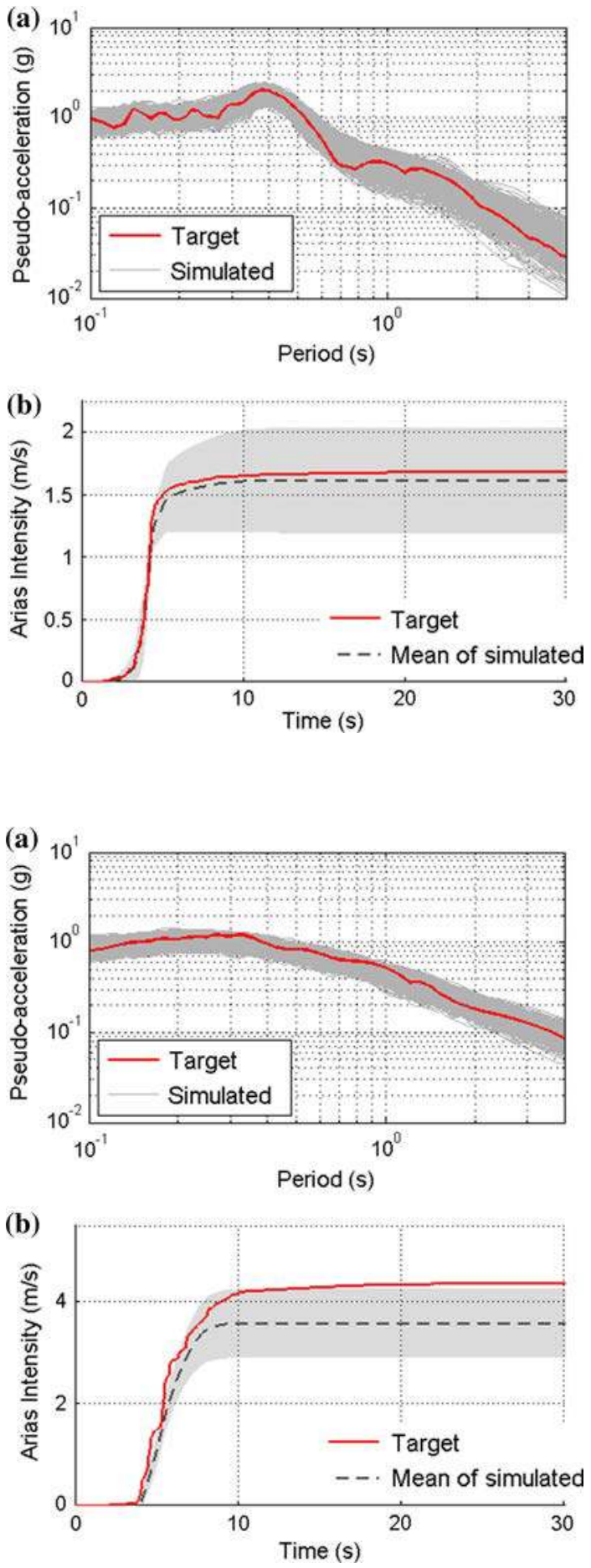
This simple approach is hereafter validated with several earthquake records. The simulated accelerograms for the Loma Prieta earthquake are shown in Fig. 11 (damping ratio $\xi=5 \%$ ). The comparisons of spectra and Arias Intensities are shown in Fig. 12. Results show that although the standard deviation is found increased especially at the end of the earthquake, the mean of the simulated Arias Intensity follows closely the target. The method is also validated for higher damping ratio earthquakes, for example the Northridge Newhall earthquake (response spectrum damping ratio $\xi=20 \%$, see Fig. 13).

Compared with the first approach presented in Sect. 3.1, the energy-based envelope shape method is not so precise. However, it requires only the modification of the envelope shape function, without introducing an additional (double) iterative process in the general Algorithm 1. The computational efficiency is thus higher than the first method. For the cases studied in this paper, 3-5 iterations are sufficient to achieve convergence.

\section{Conclusions}

In this paper, two simplified approaches are introduced to correct the Arias Intensity of synthetic artificial accelerograms for given specific earthquake records. The proposed methods enable the generation of both spectrum-compatible and energy-compatible accelerograms. The first approach matches the spectrum and energy distribution of artificial and target accelerograms with a double iterative process. The second method is an empirical approach based on the energy profile of earthquake record. The first method provides better results but with needs of more computational time. Both approaches are validated and proved to be simple and efficient tools for generating artificial accelerograms in earthquake engineering.

The Matlab subroutines for the two methods proposed in this study are available online: https://www.dropbox.com/sh/fq1jrupjwdzz7tg/AAAhuZEdZQ_QKO-Rfp3ZHPvEa?dl= 0 and

http://cn.mathworks.com/matlabcentral/fileexchange/59931-spectrum-and-energy-com patible-artificial-accelerograms

Acknowledgements The grant from Safety Assessment of Concrete Box-girder Arch Bridges (NO. of contract: 2014318223 030) supported by Research Institute of Highway Ministry of Transport of China $(\mathrm{RIOH})$ is greatly acknowledged. The authors would also like to acknowledge the SINAPS@ project (Sésisme et Installation Nucléaire: Améliorer et Pérenniser la Sureté), approved and funded by the National Agency of Research (ANR) following the RSNR 2012 call for the projects on future investments postFukushima (SINAPS@ ANR-11-RSNR-0022). The help from Mr. Jing LIU from bridge engineering center of RIOH is appreciated.

\section{Appendix 1: Commonly used envelope functions}

\section{Exponential envelope shape, Liu (1969)}

$$
q(t)=a_{0}\left(\mathrm{e}^{-\alpha t}-\mathrm{e}^{-\beta t}\right)
$$

The envelope shape proposed by Liu (1969) (with selected parameters $\alpha=0.2$ and $\beta=0.6)$ is shown in Fig. 14 . 
Fig. 14 Envelope shape proposed by Liu (1969). $\alpha=0.2$ and $\beta=0.6$

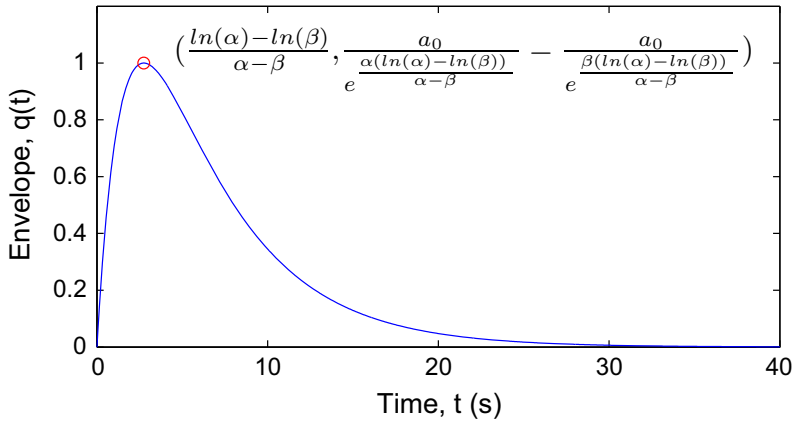

Fig. 15 Envelope shape proposed by Jennings et al. (1968). $T_{1}=3.0, T_{2}=8.0$ and $\alpha=0.2$

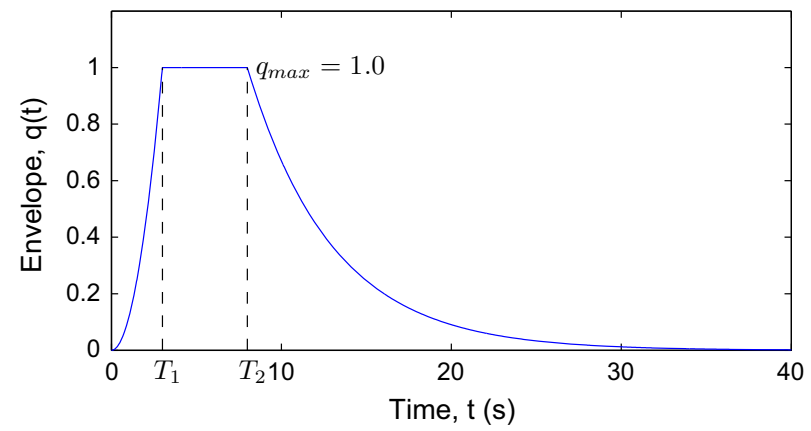

Piece-wise envelope shape Jennings et al. (1968)

In 1986, Jennings et al. (1968) propose a piece-wise envelope shape as, Eq. (11).

$$
q(t)=\left\{\begin{array}{cc}
\left(\frac{t}{T_{1}}\right)^{2} & 0 \leq t \leq T_{1} \\
1.0 & T_{1}<t \leq T_{2} \\
\mathrm{e}^{-\alpha\left(t-T_{2}\right)} & T_{2}<t \leq t_{d}
\end{array}\right.
$$

where, $T_{1}$ and $T_{2}$ denote the start and end times of an earthquake motion; $\alpha$ is the model parameter and $t_{d}$ is the total duration of an earthquake. The envelope shape with selected parameters $\left(T_{1}=3.0, T_{2}=8.0\right.$ and $\left.\alpha=0.2\right)$ is shown in Fig. 15.

\section{Gamma envelope shape proposed by Saragoni and Hart (1974)}

Saragoni and Hart (1974) proposed a 'gamma' function to simulate the temporal nonstationary. The 'gamma' function is proportional to the gamma probability density which is the reason for the name. The 'gamma' function reads:

$$
q(t)=\alpha_{1} t^{\alpha_{2}-1} \mathrm{e}^{-\alpha_{3} t}, t \geq 0
$$

The 'gamma' has its maximum equals to $\alpha_{1} \mathrm{e}^{1-\alpha_{2}}\left[\left(\alpha_{2}-1\right) / \alpha_{3}\right]^{\alpha_{2}-1}$, when $t$ is $\left(\alpha_{2}-1\right) / \alpha_{3}$. The 'gamma' envelope shape with selected parameters $\left(\alpha_{1}=0.4618, \alpha_{2}=3.0\right.$ and $\left.\alpha_{3}=0.5\right)$ is shown in Fig. 16. 
Fig. 16 Gamma envelope shape proposed by Saragoni and Hart (1974). $\alpha_{1}=0.4618, \alpha_{2}=3.0$ and $\alpha_{3}=0.5$

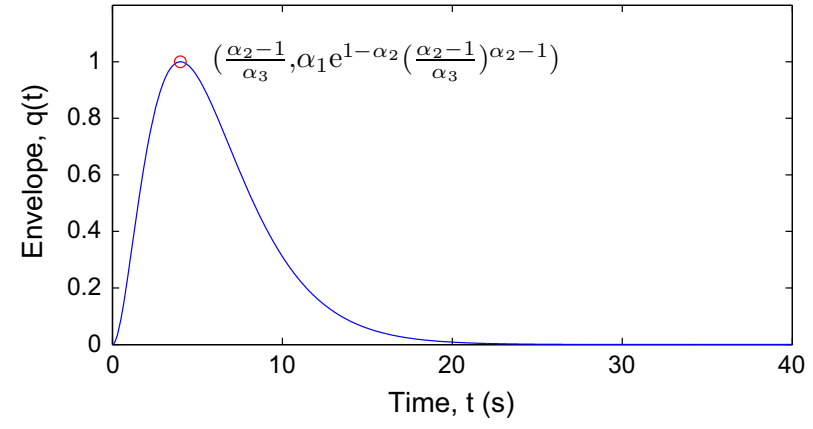

\section{Appendix 2: Matlab subroutines}

Matlab subroutine for computing energy distribution shapes of earthquake records

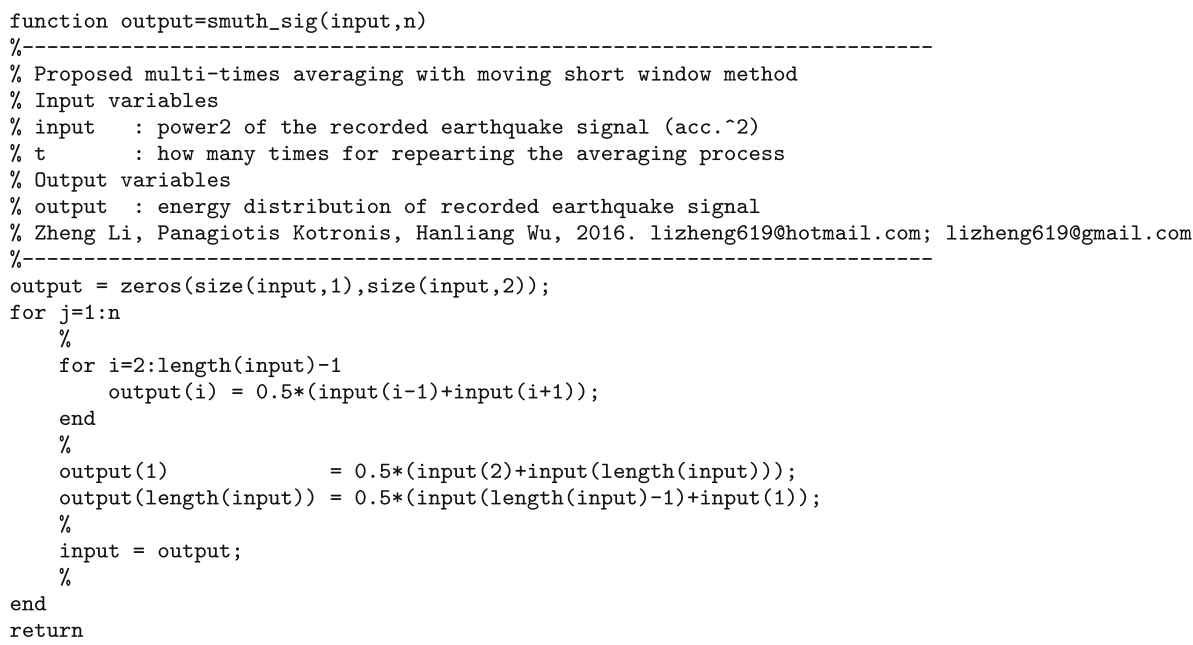




\section{Matlab subroutine for finding the envelope shapes of earthquake records}

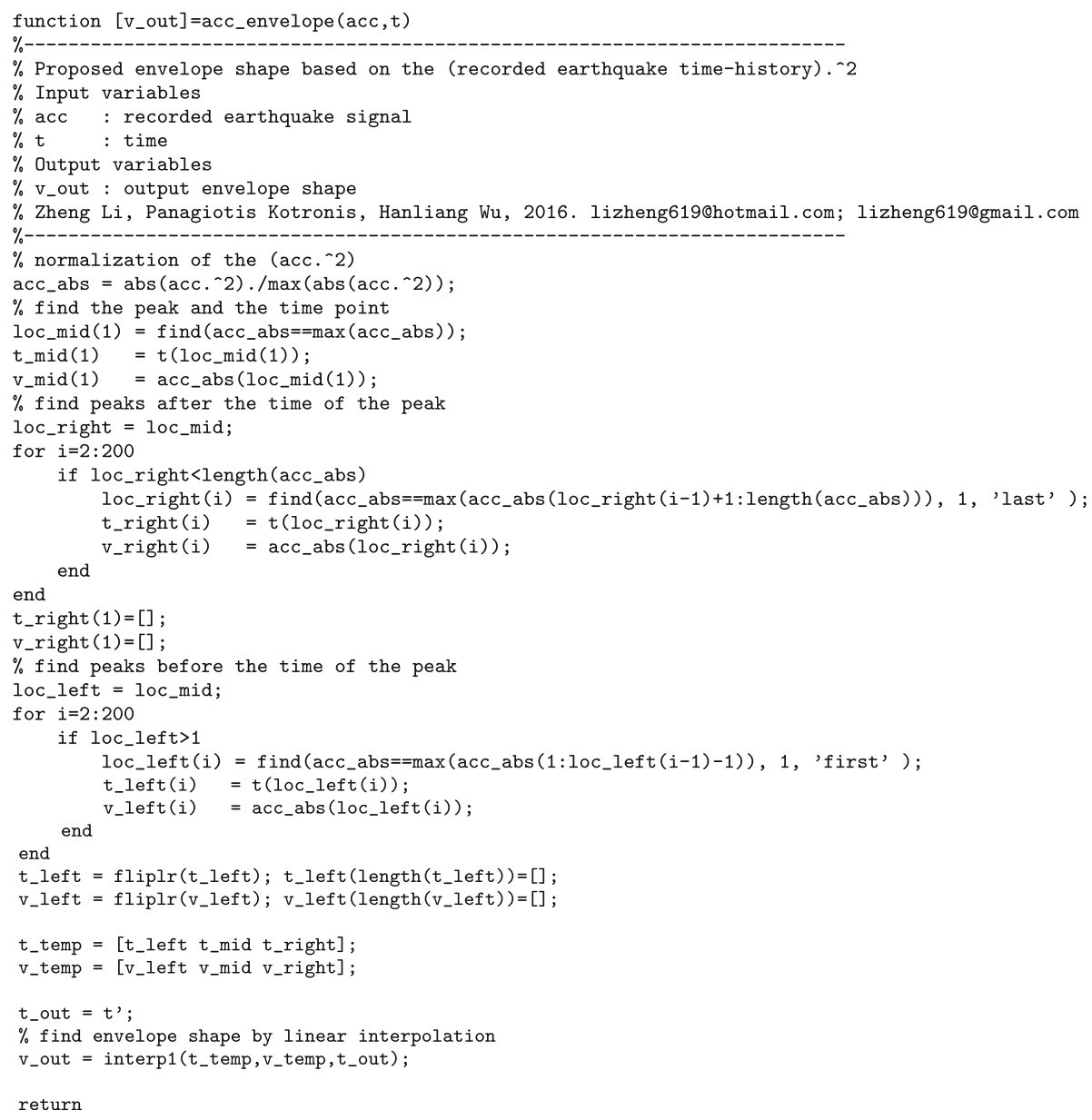

\section{References}

Arias A (1970) A measure of earthquake intensity. In: Hansen R (ed) Seismic design for nuclear power plants. MIT Press, Cambridge, pp 438-483

Boore DM (2001) Effect of baseline corrections on displacements and response spectra for several recordings of the 1999 Chi-Chi, Taiwan, earthquake. Bull Seismol Soc Am 91(5):1199-1211. doi:10. $1785 / 0120000703$

Cabañas L, Benito B, Herráiz M (1997) An approach to the measurement of the potential structural damage of earthquake ground motions. Earthq Eng Struct Dyn 26(1):79-92. doi:10.1002/(SICI)10969845(199701)26:1<79::AID-EQE624>3.0.CO;2-Y

Cacciola P, Colajanni P, Muscolino G (2004) Combination of modal responses consistent with seismic input representation. J Struct Eng 130(1):47. doi:10.1061/(ASCE)0733-9445(2004)130:1(47)

Del Gaudio V, Pierri P, Wasowski J (2003) An approach to time-probabilistic evaluation of seismically induced landslide hazard. Bull Seismol Soc Am 93(2):557-569 
Egan J, Rosidi D (1991) Assessment of earthquake-induced liquefaction using ground-motion energy characteristics. In: Proceedings of the pacific conference on earthquake engineering, Auckland, New Zealand

Gasparini DA,Vanmarcke EH (1976) Simulated earthquake motions compatible with prescribed response spectra. Research Report R76-4. Department of Civil Engineering, Massachusetts Institute of Technology, Cambridge, MA

Greco R, Fiore A, Marano GC (2014) The role of modulation function in nonstationary stochastic earthquake model. J Earthq Tsunami 8(5):1450015

Harp EL, Wilson RC (1995) Shaking intensity thresholds for rock falls and slides: evidence from 1987 Whittier Narrows and superstition hills earthquake strong-motion records. Bull Seismol Soc Am 85(6):1739-1757

Hou S (1968) Earthquake simulation models and their applications. Tech. rep., Massachusetts Institute of Technology, Department of civil engineering

Iyengar RN, Rao P (1979) Generation of spectrum compatible accelerograms. Earthq Eng Struct Dyn 7(3):253-263. doi:10.1002/eqe.4290070305

Jennings PC, Housner GW, Tsai NC (1968) Simulated earthquake motions. Tech. rep., EERL California Institute of Technology

Kaul MK (1978) Stochastic characterization of earthquakes through their response spectrum. Earthq Eng Struct Dyn 6(5):497-509. doi:10.1002/eqe.4290060506

Kayen RE, Mitchell JK (1997) Assessment of liquefaction potential during earthquakes by Arias intensity. J Geotech Geoenviron Eng 123(12):1162-1174. doi:10.1061/(ASCE)1090-0241(1997)123:12(1162)

Kramer SL, Mitchell RA (2006) Ground motion intensity measures for liquefaction hazard evaluation. Earthq Spectra 22(2):413-438. doi:10.1193/1.2194970

Kwon OS, Elnashai A (2006) The effect of material and ground motion uncertainty on the seismic vulnerability curves of RC structure. Eng Struct 28(2):289-303. doi:10.1016/j.engstruct.2005.07.010

Liu SC (1969) Autocorrelation and power spectral density functions of the parkfield earthquake of june 27 , 1966. Bull Seismol Soc Am 59(4):1475-1493

Marano GC, Morga M, Sgobba S (2013) Parameters identification of stochastic nonstationary process used in earthquake modelling. Int J Geosci 4(2):290-301

Masi A (2003) Seismic vulnerability assessment of gravity load designed R/C frames. Bull Earthq Eng 1(3):371-395. doi:10.1023/B:BEEE.0000021426.31223.60

Masi A, Vona M, Mucciarelli M (2011) Selection of natural and synthetic accelerograms for seismic vulnerability studies on reinforced concrete frames. J Struct Eng 137(3):367-378. doi:10.1061/ (ASCE)ST.1943-541X.0000209

Naeim F, Lew M (1995) On the use of design spectrum compatible time histories. Earthq Spectra 11(1):111-127. doi:10.1193/1.1585805

Nanos N, Elenas A (2006) Seismic duration effects on the vulnerability of buildings. In: First European conference on earthquake engineering and seismology

Rezaeian S (2010) Stochastic modeling and simulation of ground motions for performance-based earthquake engineering. Thesis, University of California, Berkeley

Rezaeian S, Der Kiureghian A (2010) Simulation of synthetic ground motions for specified earthquake and site characteristics. Earthq Eng Struct Dyn 39(10):1155-1180. doi:10.1002/eqe.997

Rezaeian S, Kiureghian AD (2008) A stochastic ground motion model with separable temporal and spectral nonstationarities. Earthq Eng Struct Dyn 37:1565-1584. doi:10.1002/eqe.831

Saragoni GR, Hart GC (1974) Simulation of artificial earthquakes. Earthq Eng Struct Dyn 2(3):249-267. doi:10.1002/eqe.4290020305

Seismosoft (2016) SeismoArtif. http://www.seismosoft.com

Sheng T, Shi W, Xie Y (2012) A modification method of earthquake ground motions for matching multidimensional energy input spectra and peak velocity. J Tongji Univ 40(6):807-812. doi:10.3969/j.issn. 0253-374x.2012.06.001

Spanos P, Giaralis A, Politis N (2007) Time-frequency representation of earthquake accelerograms and inelastic structural response records using the adaptive chirplet decomposition and empirical mode decomposition. Soil Dyn Earthq Eng 27(7):675-689. doi:10.1016/j.soildyn.2006.11.007

Stafford PJ, Berrill JB, Pettinga JR (2009a) New predictive equations for Arias0 intensity from crustal earthquakes in New Zealand. J Seismol 13(1):31-52. doi:10.1007/s10950-008-9114-2

Stafford PJ, Sgobba S, Marano GC (2009) An energy-based envelope function for the stochastic simulation of earthquake accelerograms. Soil Dyn Earthq Eng 29(7):1123-1133. doi:10.1016/j.soildyn.2009.01. 003

Travasarou T, Bray JD, Abrahamson NA (2003) Empirical attenuation relationship for Arias Intensity. Earthq Eng Struct Dyn 32(7):1133-1155. doi:10.1002/eqe.270 
Villaverde R (2009) Fundamental concepts of earthquake engineering. CRC Press, Boca Raton

Wang J, Fan L, Qian S, Zhou J (2002) Simulations of non-stationary frequency content and its importance to seismic assessment of structures. Earthq Eng Struct Dyn 31(4):993-1005. doi:10.1002/eqe.134

Yazdani A, Takada T (2009) Wavelet-based generation of energy- and spectrum-compatible earthquake time histories. Comput Aided Civil Infrastruct Eng 24(8):623-630. doi:10.1111/j.1467-8667.2009. 00621.x

Yeh CH, Wen YK (1990) Modeling of nonstationary ground motion and analysis of inelastic structural response. Struct Saf 8(1):281-298. doi:10.1016/0167-4730(90)90046-R

Zentner I, Poirion F (2012) Enrichment of seismic ground motion databases using Karhunen-Loève expansion. Earthq Eng Struct Dyn 41(14):1945-1957. doi:10.1002/eqe.2166

Zentner I, Humbert N, Ravet S, Viallet E (2011) Numerical methods for seismic fragility analysis of structures and components in nuclear industry-application to a reactor coolant system. Georisk 5(2):99-109. doi:10.1080/17499511003630512

Zentner I, Allain F, Humbert N, Caudron M (2014) Generation of spectrum compatible ground motion and its use in regulatory and performance-based seismic analysis. In: Cunha A, Caetano E, Ribeiro P, Müller G (eds) Proceedings of the 9th international conference on structural dynamics, EURODYN2014. Porto, Portugal, pp 381-386 